\title{
Reflexiones acerca del patrimonio nacional y turismo
}

Alvaro Barros ${ }^{1}$

Mi trabajo en estos últimos ocho años ha girado en torno al patrimonio, su defensa, restauración y aprovechamiento, por esto estoy aquí.

Dios quiera que den buen fruto mis reflexiones personales sobre esta temática universal: patrimonio natural-cultural y turismo. Bienes dados a los hombres para que les sirvan a lograr su fin, y su relación con este actualísimo fenómeno humano que es el turismo.

Es necesario, en primer lugar, definir los términos y luego intentar unos pasos más.

Patrimonio natural, o sea, bienes tal como fueron creados por Dios, como se dan en la naturaleza.

Patrimonio cultural, aquellos en los que aparece el pensamiento, la mano, el amor del hombre.

1. En ambos casos una primera connotación es su calidad de bienes heredados, o sea nos llegan por herencia.

2. Son herencia común, pertenecen a la comunidad nacional, y por lo tanto, se deben incorporar a su ordenamiento jurídico y administrativo. "Sin embargo, cada día se manifiesta con más fuerza la tendencia a considerarlos, por lo menos a los de más alta jerarquía, como patrimonio de la humanidad. Hay, entonces, diversas calidades de patrimonio.

3. Como herencia no solo implican a los ascendientes, sino a los descendientes. Se reciben, se entregan. Entran en la continuidad de la vida humana. De esto se nos pedirá cuenta.

4. Salvo su mantención y complementos que posibiliten su aprovechamiento no es necesario, en general, agregarles algo.

1 Servicio Nacional de Turismo. Ricardo Cox Méndez 1526, Santiago, CHILE.
5. De pensarse en su destrucción habría que imaginar la destrucción del hombre mismo, porque van con él, aun en aquellos casos en que todavía no los descubre.

6. Llevan entonces una tremenda connotación, su posibilidad de ser degradados hasta desaparecer, su daño, frecuentemente es, pues, irrecuperable.

7. Estos bienes son identidad de nación, de región, de pueblo, de lugar, de hombres. En esta identidad que a la vez es dignidad existe un rico campo para la pedagogía, desde la familia hasta los niveles más altos.

8. Constituyen riqueza, recurso, atractivo. No se refiere esto a lo medible en dinero, pues aunque lo sean, están a otro nivel.

9. Concitan la admiración, la búsqueda, la contemplación, el goce y crecimiento espiritual; el encuentro entre los seres humanos. Y es aquí donde está su relación con el desplazamiento de estos seres por la tierra.

10. Algo muy incentivador: nuestra propia obra puede alcanzar nivel de patrimonio; si logra trascendencia.

11. El patrimonio natural es desde el perfil inmóvil de la montaña hasta el constantemente cambiante del océano, y también el que está bajo las aguas. Es el desierto, la isla, los hielos polares. Lo conforman insectos, aves, plantas, peces... es el agua y el aire: es cualquier biotipo. Se establecen sistemas para su protección: Parques Nacionales, Reservas, Santuarios, Monumentos Nacionales, como áreas definidas con zonificaciones técnicamente establecidas según planes de manejo.

Pero la idea de patrimonio natural excede el carácter de lo único, de lo más admirable o lo legalmente más cuidado. El concepto hoy abarca 
a todo el medio natural según grados de jerarquización pues el hombre está comprendiendo que su vida es frágil en un medio frágil. A la categoría de bello y noble se agrega entonces la de vida.

12. El patrimonio cultural, por otra parte, incluyéndolos, va más allá de los testigos o monumentos ya sean del arte, la historia o la prehistoria; abarca el también asombroso campo de la tecnología y de la ciencia, implica el archivo, la biblioteca, el museo. Comprende desde lo folklórico hasta los rasgos que nos distinguen como seres humanos: costumbres, bailes, música, gastronomía, artesanía, religión, lenguaje, se suman, también según categorías, bienes materiales y espirituales.

Expuestas aquí algunas facetas definitorias de lo que son los bienes patrimoniales, veamos su conexión con un fenómeno tan antiguo como la humanidad; el desplazamiento de los seres humanos desde su habitual lugar de permanencia hacia otro sitio, por un tiempo, para conocer, distraerse, descansar, vacacionar, estudiar, comunicarse, encontrar, contemplar, orar, sanar, negociar, practicar deportes, u otro objetivo que no sea establecerse definitivamente en el sitio elegido, o permanecer allí por la fuerza. El fenómeno se llama turismo y el sujeto que lo practica, turista.

El gran motor del turismo son los atractivos del pueblo y su territorio; la forma en que ese hombre ocupa y aprovecha su medio natural, la armonía creadora de tal hombre manifestada en sus obras y el don de la naturaleza.

O sea, los atractivos son los bienes patrimoniales sumados a todo lo que constituye la acogida.

Anualmente más de 200 millones de turistas atraviesan las fronteras. El movimiento interno a nivel mundial naturalmente es muchas veces superior. Millones de trabajadores laboran para que esto ocurra a través de transportes, agencias, hospedaje, gastronomía, comunicaciones, comercio, esparcimiento, cultura, servicios estatales y todo el complejo de actividades que por una parte facilitan el fenómeno y por otra se ordenan para un beneficio a su costa.

Esto, por otra parte, implica convenciones y acuerdos internacionales públicos y privados en una trama que no es el caso detallar, pero que puede sintetizarse como un inmenso poder, un motor descomunal, múltiple, interesante, avasallador, aun cuando manejable; ineludible.

Inteligentemente conducido y aprovechado es no solo fuente enriquecedora sino un asunto necesario de considerar atenta y creadoramente en el quehacer nacional e incluso personal.

Definidos hasta aquí algunos términos, hagamos una especie de rápida diagnosis de cómo afrontamos estas realidades como nación e insinuemos brevemente ciertas proposiciones.

1. El patrimonio natural de Chile está preservado en 45 Parques Nacionales y otros tantos sistemas de reservas y santuarios. Menos de 10 tienen guardaparques y planes de manejo. Extensas áreas y regiones completas con ecosistemas únicos, como ocurre en la Región de Antofagasta, no están incluidas en el sistema. No se forma ni educa al chileno en orden a crearle amor por la naturaleza ni menos un criterio frente al patrimonio natural.

2. En cuanto al patrimonio cultural se reconocen, salvo error, cerca de 230 Monumentos Históricos Nacionales y 23 zonas típicas. Pero el Consejo de Monumentos Nacionales no es eficiente en cuanto a salvaguardar tal patrimonio por carecer de atribuciones. No existe ni ley ni institución que garantice eficientemente, o sea, que esté implementada con mecanismos prácticos para el descubrimiento, el estudio, la consolidación, la restauración y el mantenimiento de nuestros monumentos ni menos el patrimonio cultural tal como se ha definido.

La iniciativa, salvo para alguna labor del Ministerio de Obras Públicas, queda en manos de las autoridades locales pero sin respaldo legal ni económico; se consiguen los mayores éxitos a través de investigadores y científicos que laboran con su propio esfuerzo.

Nuestra educación aún no se orienta en tal sentido.

3. El fenómeno turístico irrumpe en nuestra patria, aumentando tanto en lo interno como en lo internacional. La búsqueda de atractivos ya naturales, ya culturales, crece notoriamente. 
Los mecanismos de control, ordenamiento, servicios e infraestructura son deficitarios aun cuando se haya experimentado un crecimiento destacable en las últimas décadas en materia de equipamiento.

4. Mecanismos orientados a detener la polución, contaminación, destrucción de áreas naturales e incluso culturales, son deficitarios o inexistentes.

\section{Algunas proposiciones básicas}

1. Coordinación entre instancias interesadas en la materia de nivel estatal como Ministerio de Educación, Monumentos Nacionales, Sernatur, CONAF, autoridades regionales y comunales, cuyo papel es irremplazable.

De nivel particular como defensa de flora y fauna, colegios profesionales, institutos, universidades, sociedades culturales, etc.

2. Política de uso y preservación del territorio con sentido de planificación físicocultural.

Determinación de áreas de aprovechamiento, estudio y materias vinculadas relativas tanto al patrimonio natural como al cultural.

3. Política de financiamiento para la investigación, restauración y aprovechamiento.
Planes priorizados por los especialistas.

4. Equipos interdisciplinarios para asumir tareas en estas áreas.

\section{Consideraciones finales}

Pienso que asistimos a una vertiginosa convergencia de búsqueda y explicación del hombre, ansioso de asir su origen y destino. Carrera dramática cuyo clímax, para quien quiera y pueda verlo, tiene signos de proximidad.

Las facetas intelectuales gravitan más en los especialistas; las estéticas en los que deambulan contemplando; las morales alcanzan a todos. Es un compromiso de amor, necesario como necesaria es nuestra existencia. Pero el amor tiene un paso previo indispensable que es el aprecio: reconozco que vales, posees dignidad como yo; sin embargo, el paso inicial es el respeto. Desde el respeto parte la conquista de la convivencia: respeto por las personas, por sus obras, por las cosas de Dios, en una palabra, por esta herencia patrimonial que debiéramos entregar enriquecida con todo nuestro esfuerzo.

Agradecimiento A Bente Bittmann que tuvo la amabilidad de invitarme. Gracias a Glenda Kapstein, por quien estoy aquí. Gracias a ustedes por escucharme. 